\title{
Synthesis and characterization of multifunctional gold nanoclusters for application in radiation therapy
}

This article was published in the following Dove Press journal: International Journal of Nanomedicine

\author{
Richa Baronia' \\ Manjri Singh' \\ Rajat B Gupta' \\ Stalin Karuppiah' \\ Rajiv Kumar ${ }^{2}$ \\ Jodi Belz ${ }^{2}$ \\ Rishi Shanker ${ }^{3}$ \\ Srinivas Sridhar ${ }^{2}$ \\ Surinder P Singh' \\ 'CSIR-National Physical Laboratory, \\ Dr KS Krishnan Marg, New Delhi, \\ India; ${ }^{2}$ Nanomedicine Science and \\ Technology Center, Northeastern \\ University, Boston, MA, USA; \\ ${ }^{3}$ Institute of Life Sciences, Ahmedabad \\ University, Ahmedabad, India
}

\begin{abstract}
Gold nanoparticles, because of their high radiation absorption coefficient and efficient generation of secondary photoelectrons, have been predicted to enhance therapeutic efficacy in radiation therapy. However, high dose for effective treatment limits their use. We have synthesized multifunctional gold nanoclusters (GNCs) that can be used for imaging and radiation therapy. The designed GNCs have been characterized for their physicochemical properties, biocompatibility, and their radiation dose enhancement potential on PC3 cell lines.
\end{abstract}

Keywords: gold nanoclusters, radiation therapy

\section{Introduction}

Noble metal (gold, silver, and platinum) nanoclusters (NCs) comprising of few atoms are emerging as good alternatives to quantum dots which are intrinsically toxic for bioapplications. These nanoclusters exhibit strong fluorescence which is tunable in the range of visible to near-infrared (NIR). Gold nanoclusters (GNCs) have gained tremendous attention in the field of theranostics owing to their excellent optical fluorescence, high quantum yield, easy conjugation with biological molecules, photostability, and biocompatibility.

Radiotherapy is still considered as a major modality in cancer therapy. From a therapeutic perspective, despite significant advances in technology, radiation therapy is unable to achieve local control of the primary tumor and normal tissue toxicity. The interaction of X-rays with high atomic number materials is expected to enhance the radiation doses in biological tissues through low-energy electrons produced as a result of photoelectric absorption. ${ }^{1}$ The gold nanoparticles owing to their high $Z$ value have been investigated as potential radiosensitizers in radiation therapy. However, enhancing tumor radiation dose with high atomic number (high-Z) requires large amounts of the material to be delivered to the tumor site, which poses a constraint on their practical use.

GNCs, which are clusters of 20-25 gold atoms embedded in a protein scaffold, have been shown to enhance the radiation therapy as well as have efficient clearance from the body. ${ }^{2}$ In the present study, we have synthesized gold nanoclusters using a wet chemical route for their application in radiation therapy for cancer. We investigated their biocompatibility and radiation dose enhancement potential on PC3 prostate cancer cell lines. The initial results are encouraging.
Correspondence: Surinder P Singh CSIR-National Physical Laboratory, Dr K. S. Krishnan Marg, New Delhi II0012, India

Email singhsp@nplindia.org 


\section{Materials and methods}

All the reagents used were purchased from Sigma Aldrich (St Louis, MO, USA). The PC3 cell lines were procured from the American Type Culture Collection (Manassas, VA, USA).

\section{Synthesis}

GNCs have been synthesized using an earlier reported method. ${ }^{3}$ Five milliliters of $10 \mathrm{mM} \mathrm{HAuCl}_{4}$ in deionized water was dispensed in a $25 \mathrm{~mL}$ conical flask and $5 \mathrm{~mL}$ of $0.5 \mathrm{mM}$ aqueous solution of bovine serum albumin (BSA) in water was added with vigorous stirring. Further, $0.5 \mathrm{~mL}$ of $0.5 \mathrm{M}$ aqueous sodium hydroxide solution was added to the stirring solution, and $\mathrm{pH}$ of the solution was maintained at about 10-12. The whole reaction mixture was kept in a water bath and incubated for $12 \mathrm{~h}$ at the temperature of $37^{\circ} \mathrm{C}$. After the completion of the reaction, transparent orange brown coloration was observed, indicating the formation of GNCs. The as-synthesized GNCs were filtered using $0.22 \mu \mathrm{m}$ syringe filter and lyophilized.

\section{Results and discussion}

The synthesized GNCs were characterized using Fourier transform infrared (FTIR) spectroscopy, UV-Visible spectroscopy, and photoluminesence. The size of GNCs was measured by transmission electron microscopy (TEM). GNCs were found to emit red color under illumination by ultraviolet light lamp of $365 \mathrm{~nm}$.

The FTIR spectra (data not shown) of GNCs exhibit the characteristic vibration peaks of protein BSA. The characteristic amide-I and amide-II bands of BSA related to secondary structure of protein are observed at $1,665 \mathrm{~cm}^{-1}$ and $1,529 \mathrm{~cm}^{-1}$. Peaks at $3,276 \mathrm{~cm}^{-1}$ and at $2,958 \mathrm{~cm}^{-1}$ correspond to primary amines and $\mathrm{C}-\mathrm{H}$ vibration, respectively. ${ }^{4}$ The GNCs exhibited the UV-vis absorption spectrum (data not shown) with a maximum absorption at 280 and $520 \mathrm{~nm}$. The absorption peaks at $280 \mathrm{~nm}$ are ascribed to the $\pi \rightarrow \pi^{*}$ transition of the aromatic amino acid residues of BSA, and feeble absorption at $520 \mathrm{~nm}$ could be attributed to the formation of a few gold nanoparticles. TEM image depicts formation of GNCs less than $5 \mathrm{~nm}$ (Figure 1).

Photoluminescence measurements illustrate that GNCs exhibited fluorescence peaks between 650 and $665 \mathrm{~nm}$ resulting from the gold atoms contained in GNCs core, upon excitation at wavelengths between 350 and $490 \mathrm{~nm}$. The Gaussian behavior of fluorescence emission peaks is attributed to the presence of 18, 22, 23, and 25 atom gold clusters. ${ }^{4}$ Photoluminescence emission at around $656 \mathrm{~nm}$ with excitation of $390 \mathrm{~nm}$ indicates that our sample is dominated by the presence of an 18 gold cluster. This emission was considered

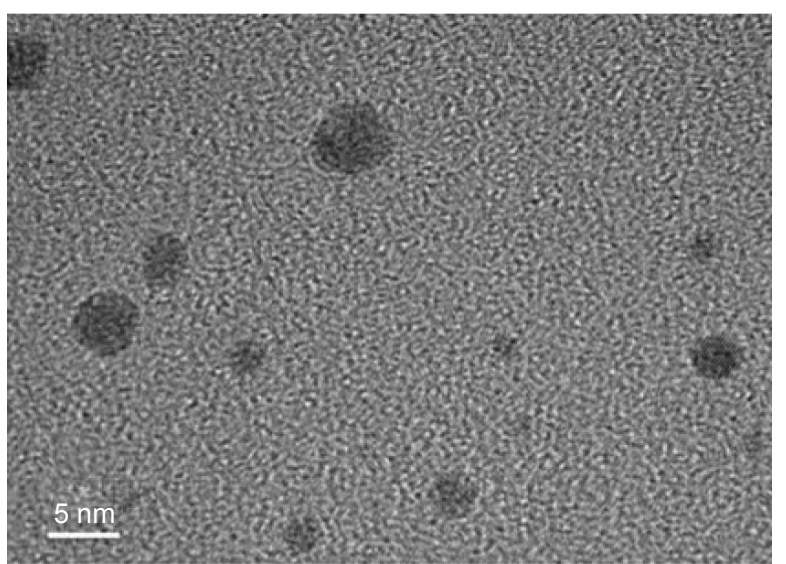

Figure I TEM image of GNCs.

Abbreviations: GNC, gold nanocluster; TEM, transmission electron microscopy.

to arise from intraband transitions of free electrons of the GNCs (Figure 2).

The cell viability was assessed using 3-(4,5-dimethy1thiazol-2-yl)-2,5-diphenyltetrazolium bromide (MTT) assay to check the biocompatibility of synthesized GNCs. For this, PC3 prostate cancer cells were dispensed in 96-well plates and allowed to adhere for $24 \mathrm{~h}$. After adherence, different concentrations of the GNCs were then added to each well. The effect of the concentration of GNCs was assessed using cell viability assay on PC-3 prostate cancer cell lines. The percentage of cell growth inhibition was assayed by the number of surviving cells after $24 \mathrm{~h}$ incubation. It was observed that there was no significant cell death, and a $97 \%$ cell viability was recorded even at the higher concentration $(0.4 \mathrm{mg} / \mathrm{mL})$ of GNCs (Figure 3).

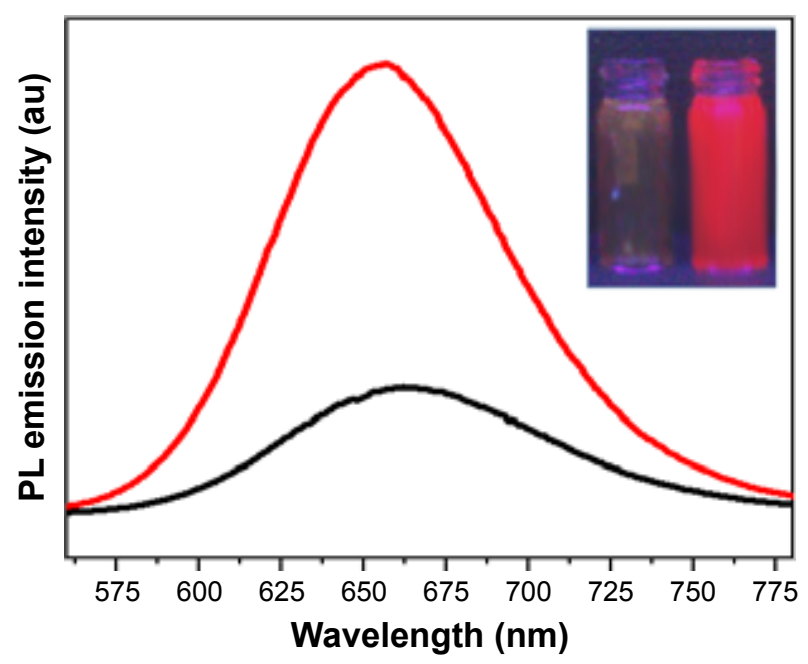

Figure 2 Photoluminescence of GNCs and fluorescence of GNCs under UV Illumination (inset).

Notes: Black line: $350 \mathrm{~nm}$ excitation wavelength; red line: $490 \mathrm{~nm}$ excitation wavelength.

Abbreviations: GNC, gold nanocluster; PL, photoluminescence; UV, ultraviolet. 


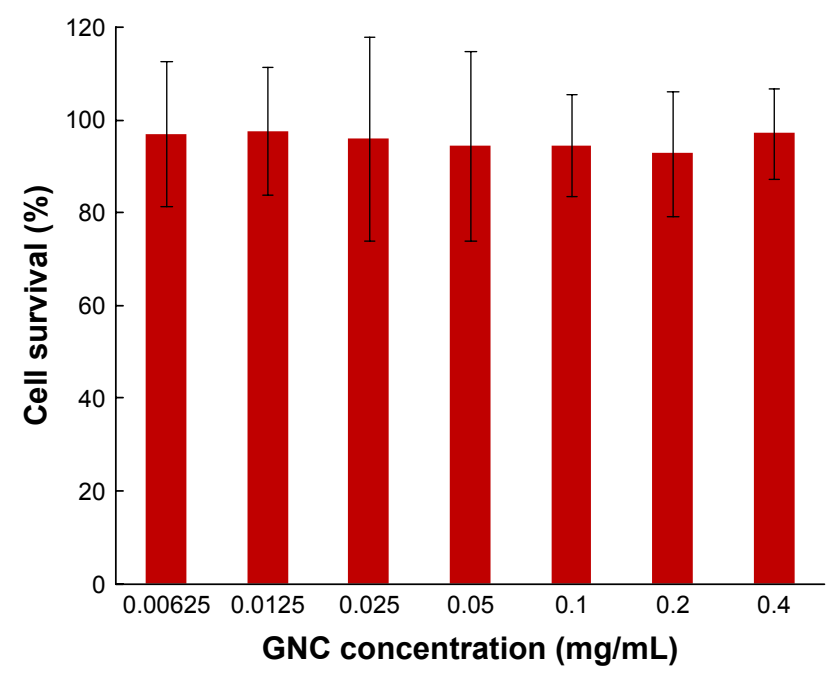

Figure 3 Cell viability assay.

Abbreviation: GNC, gold nanocluster.

\section{Radiation dose enhancement}

The clonogenic assay is a more stringent assay for cell viability studies upon irradiation with $\mathrm{X}$-rays. In vitro radiation dose enhancement studies with GNCs were carried out on PC3 cell lines using clonogenic cell survival assay. The colony formation of PC3 cells treated with GNCs at 2Gy $\mathrm{X}$-ray radiation was assessed for 2 weeks post-irradiation.

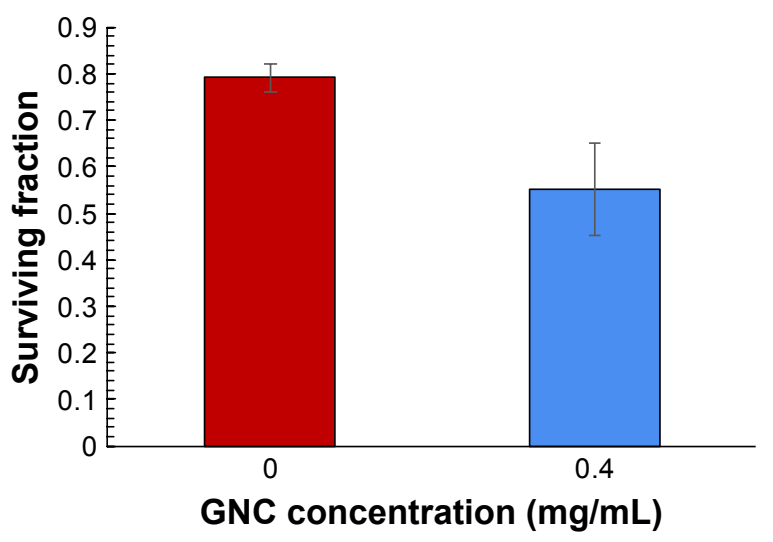

Figure 4 Clonogenic assay on PC3 cells without and with GNCs using 2Gy of X-ray dose.

Abbreviation: GNC, gold nanocluster.
Figure 4 shows the cell survival fraction for X-ray irradiated cells without or with GNCs. A $45 \%$ cell death is observed at very low concentration $(0.4 \mathrm{mg} / \mathrm{mL})$ of GNCs, which is comparable to a dose of $2 \mathrm{mg} / \mathrm{mL}$ of gold nanoparticles for a similar effect. ${ }^{1}$ Results suggest that GNCs are a potential candidate for enhancing the therapeutic radiation effect.

\section{Conclusion}

We have successfully synthesized highly luminescent gold nanoclusters of around 2-4 nm in size. The observation of $97 \%$ in cell viability assays clearly indicates the nontoxic nature of these GNCs and their potential use in bioapplications such as imaging and drug delivery. Further, the possibility of using these GNCs as radiosensitizers may bring a paradigm shift in cancer radiation therapy.

\section{Acknowledgment}

Funding from IUSSTF funded joint center on nanomedicines for head and neck cancer (GAP 130932) and NSF-IGERT are gratefully acknowledged.

\section{Disclosure}

The authors report no conflicts of interest in this work.

\section{References}

1. Kumar R, Korideck H, Ngwa W, Berbeco RI, Makrigiorgos GM, Sridhar S. Third generation gold nanoplatform optimized for radiation therapy. Transl Cancer Res. 2013;2(4):228-239.

2. Dorsey JF, Sun L, Joh DY, et al. Gold nanoparticles in radiation research: potential applications for imaging and radiosensitization. Transl Cancer Res. 2013;4:280-291.

3. Xie J, Zheng Y, Ying JY. Protein-directed synthesis of highly fluorescent gold nanoclusters. J Am Chem Soc. 2009;131(3):888-889.

4. Guevel XL, Hotzer B, Jung G, Schneider M. NIR-emitting fluorescent gold nanoclusters doped in silica nanoparticles $J$ Mater Chem. 2011;21:2974.

\section{Publish your work in this journal}

The International Journal of Nanomedicine is an international, peerreviewed journal focusing on the application of nanotechnology in diagnostics, therapeutics, and drug delivery systems throughout the biomedical field. This journal is indexed on PubMed Central, MedLine, CAS, SciSearch ${ }^{\circledR}$, Current Contents ${ }^{\circledR} /$ Clinical Medicine,

\section{Dovepress}

Journal Citation Reports/Science Edition, EMBase, Scopus and the Elsevier Bibliographic databases. The manuscript management system is completely online and includes a very quick and fair peer-review system, which is all easy to use. Visit http://www.dovepress.com/ testimonials.php to read real quotes from published authors. 